\title{
Análise da volatilidade dos preços da indústria canavieira: uma aplicação dos modelos da família $\mathrm{ARCH}$
}

\author{
Felipe Nogueira da Cruz ${ }^{1}$ \\ Mariane Santos Françoso ${ }^{2}$
}

\begin{abstract}
Resumo:
Por meio da utilização de extensões do modelo de heterocedasticidade condicional (família ARCH), este artigo procurou caracterizar a volatilidade das séries de retornos semanais dos produtos da indústria canavieira: açúcar cristal, etanol anidro e etanol hidratado. O teste ARCH, de Engle, e a estimação do GARCH e IGARCH forneceram fortes evidências de que distúrbios irregulares nos preços dessas commodities podem provocar períodos de instabilidade no setor sucroalcooleiro. Níveis mais elevados de volatilidade foram encontrados na série de retorno do açúcar cristal e observou-se maior persistência temporal dos choques nas séries de retornos do etanol anidro e hidratado.
\end{abstract}

Palavras-chave: volatilidade dos preços agropecuários, açúcar cristal, etanol anidro, etanol hidratado.

Analysis of price volatility in sugarcane industry: an application of $\mathrm{ARCH}$ family models

\begin{abstract}
:
Through the use of extensions of the conditional heteroskedasticity model (ARCH family), this article was aimed at characterizing the volatility of weekly returns of the products of the sugarcane industry: crystal sugar, anhydrous ethanol and hydrous ethanol. Both the Engle's ARCH test and the estimation of GARCH and IGARCH provided strong evidence that irregular disturbances in commodities prices can cause periods of instability in this industry. The highest levels of volatility were found in the crystal sugar series, while the larger temporal persistence of shock was observed in the anhydrous ethanol and hydrous ethanol series.
\end{abstract}

Keywords: agricultural price volatility, crystal sugar, anhydrous ethanol, hydrous ethanol.

Classificação JEL: O13, Q11.

1 Doutorando em Ciência Econômica pela Universidade Estadual de Campinas. E-mail: felipenogueirabg@hotmail.com

2 Doutoranda em Ciência Econômica pela Universidade Estadual de Campinas. E-mail: marisfrancoso@gmail.com 


\section{Introdução}

O Brasil é o maior produtor mundial de cana-de-açúcar com, aproximadamente, 630 milhões de toneladas processadas na safra de 2014/2015 e, em 2014, esse setor foi o terceiro segmento na pauta de exportações do agronegócio em termos de geração de divisas externas (UNICA, 2015). Os produtos gerados nessa indústria, álcool e etanol, são obtidos por meio de um regime flexível, no qual há a possibilidade de variação dos produtos finais obtidos a partir da cana. Essa variação é motivada principalmente pelo preço (WILKINSON, 2015).

O etanol vem sendo utilizado no Brasil desde a década de 1920, mas foi nos anos 1970 que este ganhou destaque com a criação do Pró-álcool, programa que incentivou a produção de álcool internamente. Em um contexto de crise energética mundial, com os dois choques do petróleo e o aumento significativo dos preços do barril, o programa tinha como fim a diminuição da dependência do país sobre o mercado de petróleo importado (LEITE; LEAL, 2007; JOÃO; PORTO; GALINA, 2011).

O espaço conquistado pelo etanol na matriz energética brasileira foi diminuído ao longo dos anos 1990. Com a incerteza política do começo da década, os baixos preços e a consequente estagnação da produção de etanol, a quantidade de carros a álcool, herança dos períodos anteriores, foi reduzida e o mercado voltou-se para os automóveis movidos a gasolina. Com isso, houve um aumento do consumo de etanol anidro, que era misturado à gasolina, mas uma queda no consumo de etanol hidratado, utilizado nos carros movidos exclusivamente a álcool (FURTADO; CORTEZ; SCANDIFFIO, 2008).

No início dos anos 2000, a indústria do etanol recuperou o fôlego com a introdução dos veículos com motor flexfuel no país, que passaram a ser abastecidos tanto com gasolina quanto com álcool. Outro fator propulsor foi o aumento da quantidade obrigatória de etanol anidro a ser adicionado à gasolina. $\mathrm{O}$ setor viveu um salto considerável no período de 2006 a 2008, com a produção de etanol atingindo o montante aproximado de 26,6 bilhões de litros na safra 2008/2009. Entre a safra 2004/2005 e 2009/2010, a produção de cana-de-açúcar cresceu cerca de $45 \%$, sendo que a área de cultivo superou 7 milhões de hectares nesta última safra (Tabela $1)$. 
Tabela 1 - Área de cultivo, produção e produtividade do setor sucroalcooleiro no Brasil

\begin{tabular}{cccccc}
\hline Ano-Safra & $\begin{array}{c}\text { Área Cultivo } \\
\text { Cana } \\
\text { (mil hectares) }\end{array}$ & $\begin{array}{c}\text { Produção Cana } \\
\text { (mil toneladas) }\end{array}$ & $\begin{array}{c}\text { Produtivida- } \\
\text { de (kg/ha) }\end{array}$ & $\begin{array}{c}\text { Produção } \\
\text { Açúcar } \\
\text { (mil tonela- } \\
\text { das) }\end{array}$ & $\begin{array}{c}\text { Produção } \\
\text { Etanol } \\
\text { (mil litros) }\end{array}$ \\
\hline $\mathbf{2 0 0 4 / 0 5}$ & $5.625,3$ & $415.694,5$ & 73.897 & $26.621,2$ & 15.416 .668 \\
$\mathbf{2 0 0 5 / 0 6}$ & $5.840,3$ & $431.413,4$ & 74.318 & $26.420,1$ & $16.851 .488,6$ \\
$\mathbf{2 0 0 6 / 0 7}$ & $6.163,3$ & $474.800,4$ & 77.038 & $30.223,6$ & $17.432 .178,0$ \\
$\mathbf{2 0 0 7 / 0 8}$ & $7.010,2$ & $571.370,7$ & 81.506 & $31.279,7$ & $23.007 .167,8$ \\
$\mathbf{2 0 0 8 / 0 9}$ & $7.057,9$ & $571.434,3$ & 80.965 & $31.620,2$ & $26.683 .424,9$ \\
$\mathbf{2 0 0 9 / 1 0}$ & $7.409,5$ & $604.513,7$ & 81.585 & $33.074,7$ & $25.762 .622,7$ \\
$\mathbf{2 0 1 0 / 1 1}$ & $8.056,1$ & $623.905,3$ & 77.446 & $38.168,4$ & $27.595 .483,3$ \\
$\mathbf{2 0 1 1} / \mathbf{1 2}$ & $8.362,6$ & $560.955,2$ & 67.081 & $38.271,8$ & $23.427 .171,0$ \\
$\mathbf{2 0 1 2} / \mathbf{1 3}$ & $8.485,0$ & $588.915,7$ & 69.407 & $38.336,9$ & $23.640 .465,1$ \\
$\mathbf{2 0 1 3} / \mathbf{1 4}$ & $8.811,4$ & $658.822,3$ & 74.769 & $37.878,3$ & $27.956 .711,5$ \\
$\mathbf{2 0 1 4 / 1 5}$ & $9.004,5$ & $634.767,0$ & 70.495 & $35.560,2$ & $28.659 .927,7$ \\
$\mathbf{2 0 1 5 / 1 6}$ & $8.654,8$ & $665.586,2$ & 76.903 & $33.489,1$ & $30.461 .524,5$ \\
\hline
\end{tabular}

Fonte: Elaboração própria a partir de dados da Conab (2016).

A recente crise financeira e econômica mundial, iniciada em 2007 no setor de crédito imobiliário norte-americano, promoveu impactos significativos sobre a indústria sucroalcooleira. Houve redução abrupta das linhas de crédito para o setor e diminuição dos investimentos na renovação de canaviais, tratos culturais e adubação. O resultado foi uma queda acentuada dos níveis de produtividade, que atingiu 67 toneladas por hectare na safra 2011/2012, uma redução de $21,5 \%$ em relação à produtividade correspondente à safra 2007/2008 (Tabela 1). Além disso, muitas usinas que haviam contraído dívidas denominadas em dólar no período anterior tornaram-se financeiramente insustentáveis. O setor somou um prejuízo de mais de R\$ 4 bilhões, levando à falência inúmeras usinas (WILKINSON, 2015; UNICA, 2015).

A estagnação foi seguida por descobertas de novas reservas de petróleo no Brasil, o pré-sal, que contribuiu para uma reorientação da política energética brasileira. Essa reorientação foi acompanhada por uma política de controle do preço da gasolina como estratégia de combate à inflação no primeiro governo Dilma. Com o preço baixo da gasolina e as atenções voltadas ao pré-sal, o etanol foi deixado em segundo plano e sua competitividade caiu significativamente. Os preços do etanol, em muitos casos, não mais eram capazes de cobrir os custos da produção, agravando o endividamento do setor sucroalcooleiro (WILKINSON, 2015).

Apesar dos holofotes voltados para o pré-sal, a indústria canavieira não foi completamente negligenciada e alguns incentivos foram concedidos. Em 2012, o 
BNDES (Banco Nacional de Desenvolvimento Econômico e Social) disponibilizou uma linha de crédito especial para a renovação de canaviais no montante de R 4 bilhões. Outras medidas importantes também foram implementadas em 2014 e 2015: reintrodução da taxa CIDE (Contribuição de Intervenção no Domínio Econômico) sobre a gasolina; aumento da mistura de etanol na gasolina para $27 \%$; eliminação da taxa de ICMS (imposto sobre operações relativas à circulação de mercadorias e sobre prestações de serviços de transporte interestadual, intermunicipal e de comunicação) para o álcool em Minas Gerais. Como consequência, o etanol passou a ter um preço competitivo nas bombas em diversas regiões, tornando sua produção novamente lucrativa (WILKINSON, 2015). A safra 2015/2016 registrou um volume recorde de 30,4 bilhões de litros de etanol.

Os impactos estruturais da crise e os desafios que o setor sucroalcooleiro enfrenta, contudo, continuam. De acordo com Luiz Augusto Barbosa Cortez, especialista em bionergia, a falta de planejamento do governo é a principal causa para a crise do etanol. A ausência de uma política com efeitos de longo prazo inibe a consolidação da indústria sucroenergética (BBC BRASIL, 2013). Com base nessa constatação, e considerando a importância da variável preço para a elaboração de estratégias para o setor, este estudo se propõe a analisar a volatilidade dos retornos semanais dos produtos derivados da cana: açúcar cristal, etanol anidro e etanol hidratado. Especificamente, pretende-se examinar a persistência de choques e a existência de assimetrias na volatilidade dos retornos dessas commodities.

De acordo com Saith e Kamitani (2012), um choque que gere o declínio ou o aumento do preço de uma commodity pode implicar períodos de intensa instabilidade em seu mercado, com perdas consideráveis. Sendo assim, a produção agropecuária necessita de instrumentos que minimizem o risco e auxiliem o processo de tomada de decisão dos agentes do agronegócio. Nessa mesma direção, Campos (2007) advoga a necessidade de se conhecer o padrão de flutuação sazonal ou volatilidade dos preços agropecuários para que possam ser implementadas políticas de estabilização ao longo do ano. Nas palavras desse autor, “(...) a formação do preço, como elemento controlador do mecanismo de troca, reveste-se de singular importância para o Governo na formulação e na aplicação de políticas eficientemente direcionadas ao setor agropecuário" (CAMPOS, 2007, p. 304). Nesse sentido, espera-se que a análise da volatilidade dos preços da indústria canavieira contribua com o processo de antecipação e/ou com um maior entendimento dos efeitos dos choques, gerando evidências relevantes para a formulação de políticas para o setor.

$\mathrm{O}$ presente artigo divide-se em cinco seções, incluindo esta introdução. $\mathrm{Na}$ segunda seção, consta uma revisão de literatura em que são apresentados alguns estudos econométricos sobre variações nos preços de commodities agrícolas. A terceira seção descreve a metodologia aplicada para alcançar os objetivos propostos, elucidando o método estatístico empregado, a seleção e o tratamento das variáveis. O procedimento consiste na estimação dos modelos GARH, IGARCH e TARCH. Em seguida, a quarta seção discute os resultados da análise de volatilidade das séries de retornos da indústria canavieira. Por fim, na quinta seção são feitas as considerações finais. 


\section{Revisão de literatura}

Não raramente observa-se a ocorrência de distúrbios irregulares que afetam as condições de demanda e oferta do mercado agropecuário. Esses choques podem apresentar origens diversas: dificuldades impostas ao planejamento da produção; instabilidade no abastecimento devido a alterações climáticas e surtos de doenças epidemiológicas; flutuações nos índices de preços em razão da queda ou da intensidade das colheitas, de oscilações nos mercados internacionais e das variações cambiais; alterações nas políticas econômicas domésticas e externas (MATTOS; CASSUCE; MÜLLER, 2006; CAMPOS, 2007).

A absorção dos choques nesse setor ocorre por meio de ajustes nos preços dos produtos agropecuários, ajustes estes dependentes da magnitude e da persistência dos distúrbios. Considerando que as flutuações cíclicas ou sazonais dos preços provocam instabilidade, tanto nas rendas dos produtores e investidores quanto nas despesas dos consumidores, tais oscilações podem ser interpretadas como o grau de risco ou de incerteza a que estão submetidos esses agentes.

A análise do comportamento das séries históricas de preços é de fundamental relevância para a economia, uma vez que praticamente todas as fases das relações econômicas estão diretamente relacionadas com essa variável. Particularmente, o exame dos preços agropecuários configura-se como um exercício de interesse geral, dada a expressiva participação das atividades ligadas ao agronegócio no Produto Interno Bruto (PIB) brasileiro, bem como as interações dessas atividades com os demais setores da economia nacional.

A Econometria oferece um conjunto de técnicas estatísticas capazes de captar a persistência de choques sobre o retorno de séries econômicas e, também, a assimetria desses distúrbios. Saith e Kamitani (2012), por exemplo, apontam que a modelagem da variância condicional das séries de preços constitui uma importante ferramenta para compreensão do padrão de comportamento dessas variáveis, fornecendo suporte a um melhor planejamento da atividade econômica.

Tentativas de fornecer subsídios para o delineamento de estratégias adequadas, para o gerenciamento do risco de variações nos preços (retornos) de commodities agrícolas, com base na Econometria, são apresentadas em diversos trabalhos (SILVA; SÁFADI; CASTRO JÚNIOR, 2005; MATTOS; CASSUCE; MÜLLER, 2006; CAMPOS, 2007; CAMPOS; PIACENTI, 2007; SAITH; KAMITANI, 2012; MARGARIDO; AZEVEDO; SHIKIDA, 2012; CASTRO JÚNIOR; SILVA, 2013; FERREIRA; DANIEL; LIMA, 2016). Tais estudos procuram caracterizar e analisar a volatilidade das séries de retornos de produtos agropecuários a partir de extensões do modelo de heterocedasticidade condicional (família ARCH).

Saith e Kamitani (2012) aplicaram as variantes do modelo ARCH para investigar a volatilidade de três das principais commodities brasileiras: café, milho e soja. A estimação econométrica mostrou que os retornos diários dos preços de todos os produtos examinados possuem alta volatilidade. Tais resultados corroboraram 
aqueles alcançados por Campos (2007). No caso desse último estudo, o autor verificou a presença de heterocedasticidade condicional nas séries de retornos mensais da soja, café, milho e boi gordo. Ao observar os somatórios do coeficiente de reação (ARCH) com o coeficiente de persistência (GARCH), para as quatro commodities investigadas, Campos (2007) constatou valores próximos ou superiores à unidade, o que revela que os choques na volatilidade desses produtos perduram por um longo tempo.

A pesquisa de Saith e Kamitani (2012) também identificou a presença de assimetria nas séries de retorno do café e milho, indicando que choques negativos sobre a volatilidade têm maior impacto do que choques positivos, levando, portanto, maior tempo para se dissipar. Em um trabalho anterior, Silva, Sáfadi e Castro Júnior (2005) já haviam detectado fortes sinais de persistência e assimetria na volatilidade dos retornos desses dois produtos agrícolas.

Mattos, Cassuce e Müller (2006) realizaram uma análise da volatilidade do retorno mensal do boi gordo. A estimação dos modelos GARCH e TARCH indicou que a variância condicional da série, sob a ocorrência de choques, tende a crescer com o tempo. A presença de assimetria, por sua vez, foi rejeitada com base nos modelos TARCH e EGARCH. Campos e Piacenti (2007) aplicaram essas mesmas extensões da classe de modelos de heterocedasticidade condicional para delinear estratégias adequadas para o gerenciamento do risco de variações nos retornos de três produtos agroenergéticos: soja, mamona e cana-de-açúcar. Verificou-se que os somatórios dos coeficientes de reação e de persistência aproximaram-se da unidade, indicando que os choques na volatilidade levam algum tempo para se dissipar. Ademais, as culturas da mamona e cana-de-açúcar apresentaram variância condicional assimétrica, dessa forma, para a cana-de-açúcar constatou-se também a presença do efeito alavancagem 3.

Castro Júnior e Silva (2013) analisaram o comportamento dos retornos dos preços do óleo de girassol, relacionando-o aos possíveis riscos aos produtores, dadas as variações de preços sobre o óleo. Para isso, os autores utilizaram os modelos ARCH, GARCH e TARCH. Através da análise empregada, foi constatado que a variabilidade dos retornos do óleo de girassol possui dependência condicional e baixa persistência na resposta aos choques na variância, reduzindo riscos de produção com relação aos preços dos produtores.

Ferreira, Daniel e Lima (2016) buscaram verificar se os preços da mamona na Bahia estavam sujeitos à instabilidade estrutural e, também, analisar o impacto do Programa Nacional de Produção e Uso do Biodiesel (PNPB) sobre tal instabilidade. Utilizando dados sobre preços recebidos pelos produtores, pela saca de $60 \mathrm{~kg}$ da mamona na Bahia, de frequência semanal, de 09 de janeiro de 2002 a 29 de junho

Verifica-se a presença do efeito alavancagem quando os períodos de queda no preço do produto são marcados por intensa volatilidade, enquanto que períodos de alta nesse mesmo preço apresentam uma volatilidade mais baixa. 
de 2011, totalizando 488 observações, os autores empregaram modelos TGARCH e EGARCH. Eles concluíram que os preços da mamona na Bahia são instáveis e os aumentos nos preços elevam a instabilidade. Além disso, constatou-se, também, que o PNPB aumentou o risco de preço no estado.

Margarido, Azevedo e Shikida (2012) também utilizaram os modelos das famílias ARCH/GARCH para examinar a série de preços semanais do etanol anidro, no estado de São Paulo. O objetivo do trabalho foi investigar a eficiência de ajuste a choques e se há evidências de coordenação oligopolista no mercado de etanol. Verificou-se uma elevada volatilidade, porém com rápida diluição dos choques de preços e ausência de assimetria. Os resultados corroboram as hipóteses de um mercado concorrencial e ressaltam que o movimento recente de concentração produtiva foi insuficiente para impor rigidez à formação do preço do etanol.

O Quadro 1 sintetiza, em ordem cronológica de publicação, os diversos trabalhos descritos, apresentando os objetivos, variáveis e métodos utilizados, bem como os resultados alcançados em cada um deles.

Quadro 1 - Aplicação de modelos da classe ARCH e resultados obtidos em estudos selecionados

\begin{tabular}{|c|c|c|c|}
\hline & OBJETIVO & VARIÁVEIS E MÉTODOS & RESULTADOS \\
\hline $\begin{array}{l}\text { Silva, Sáfadi e } \\
\text { Castro Júnior } \\
\text { (2005) }\end{array}$ & $\begin{array}{l}\text { Examinar o processo } \\
\text { de volatilidade dos } \\
\text { retornos do café e } \\
\text { da soja }\end{array}$ & $\begin{array}{l}\text { Séries de preços mensais à vis- } \\
\text { ta em dólares do café em coco } \\
\text { (preço/kg - 1967-2002) e da } \\
\text { soja em farelo (preço/tonelada } \\
\text { métrica - 1957-2002) obtidas } \\
\text { da base de dados do IPEA; } \\
\text { aplicação dos modelos GAR- } \\
\text { CH, EGARCH e TARCH }\end{array}$ & $\begin{array}{c}\text { Sinais de persistência e assimetria } \\
\text { na volatilidade de ambas as séries; a } \\
\text { criação e o fomento de instrumen- } \\
\text { tos de hedging podem ser estraté- } \\
\text { gias adequadas em face da grande } \\
\text { volatilidade e persistência acentuada } \\
\text { de choques sobre os retornos dessas } \\
\text { commodities }\end{array}$ \\
\hline $\begin{array}{c}\text { Mattos, Cas- } \\
\text { suce e Müller } \\
\text { (2006) }\end{array}$ & $\begin{array}{l}\text { Analisar o processo } \\
\text { de volatilidade do } \\
\text { retorno mensal do } \\
\text { boi gordo }\end{array}$ & $\begin{array}{l}\text { Série mensal do preço médio } \\
\text { recebido pelo produtor do boi } \\
\text { gordo em corte (entre } 1967 \text { e } \\
\text { 2005) obtida da Revista Agro- } \\
\text { analysis da FGV; aplicação dos } \\
\text { modelos GARCH, EGARCH } \\
\text { e TARCH }\end{array}$ & $\begin{array}{l}\text { A estimação dos modelos GARCH } \\
\text { e TARCH indicou que a variância } \\
\text { condicional da série, sob a ocor- } \\
\text { rência de choques, tende a crescer } \\
\text { no tempo; a presença de assimetria } \\
\text { foi rejeitada com base nos modelos } \\
\text { TARCH e EGARCH }\end{array}$ \\
\hline $\begin{array}{c}\text { Campos } \\
(2007)\end{array}$ & $\begin{array}{l}\text { Caracterizar e exa- } \\
\text { minar a volatilidade } \\
\text { das séries de retornos } \\
\text { mensais da soja, café, } \\
\text { milho e boi gordo }\end{array}$ & $\begin{array}{c}\text { Séries de preços mensais } \\
\text { (entre 1967 e 2006) obtidas } \\
\text { da base de dados da FGV } \\
\text { - Preços Agropecuários; } \\
\text { aplicação dos modelos ARCH } \\
\text { e GARCH }\end{array}$ & $\begin{array}{c}\text { Presença de heterocedasticidade } \\
\text { condicional nos retornos das séries; } \\
\text { o somatório dos coeficientes de re- } \\
\text { ação e de persistência aproximou-se } \\
\text { ou excedeu a unidade, revelando que } \\
\text { choques na volatilidade perduram } \\
\text { por longo tempo }\end{array}$ \\
\hline
\end{tabular}




\begin{tabular}{|c|c|c|c|}
\hline $\begin{array}{l}\text { Campos } \\
\text { e Piacenti } \\
(2007)\end{array}$ & $\begin{array}{l}\text { Caracterizar e } \\
\text { analisar a volatilidade } \\
\text { das séries de retornos } \\
\text { mensais dos produtos } \\
\text { agroenergéticos: soja, } \\
\text { mamona e cana-de- } \\
\text {-açúcar }\end{array}$ & $\begin{array}{l}\text { Séries de preços mensais } \\
\text { (entre } 1967 \text { e 2006) obtidas da } \\
\text { base de dados da FGV; apli- } \\
\text { cação dos modelos ARCH/ } \\
\text { GARCH e suas extensões } \\
\text { (TARCH e EGARCH) }\end{array}$ & $\begin{array}{l}\text { Somatório dos coeficientes de reação } \\
\text { e de persistência aproximou-se da } \\
\text { unidade, indicando que os choques } \\
\text { na volatilidade perduram por algum } \\
\text { tempo; as culturas da mamona e } \\
\text { cana-de-açúcar apresentaram variân- } \\
\text { cia condicional assimétrica; presença } \\
\text { de efeito alavancagem no mercado de } \\
\text { cana-de-açúcar }\end{array}$ \\
\hline $\begin{array}{c}\text { Saith e Kami- } \\
\text { tani (2012) }\end{array}$ & $\begin{array}{l}\text { Estimar e analisar a } \\
\text { volatilidade no mer- } \\
\text { cado agropecuário } \\
\text { brasileiro, tomando } \\
\text { como base três das } \\
\text { principais commodi- } \\
\text { ties: milho, café e soja }\end{array}$ & $\begin{array}{l}\text { Séries de preços diários (entre } \\
2005 \text { e 2011) obtidas na base } \\
\text { de dados do CEPEA/ESALQ; } \\
\text { aplicação dos modelos } \\
\text { ARCH, GARCH e TARCH }\end{array}$ & $\begin{array}{l}\text { Alta volatilidade dos retornos diários } \\
\text { dos preços das commodities, sendo } \\
\text { que a soja apresentou os maiores } \\
\text { coeficientes de reação e persistência; } \\
\text { assimetria de choques apenas nos } \\
\text { mercados de café e milho }\end{array}$ \\
\hline $\begin{array}{l}\text { Margarido, } \\
\text { Azevedo } \\
\text { e Shikida } \\
\text { (2012) }\end{array}$ & $\begin{array}{l}\text { Verificar a presença } \\
\text { de volatilidade e de } \\
\text { assimetria na série } \\
\text { de preços semanais } \\
\text { do etanol anidro no } \\
\text { estado de São Paulo }\end{array}$ & $\begin{array}{l}\text { Série de preços semanais } \\
\text { (2002-2010) obtida na base de } \\
\text { dados do CEPEA/ESALQ; } \\
\text { aplicação dos modelos da } \\
\text { família ARCH/GARCH }\end{array}$ & $\begin{array}{c}\text { Apesar da alta volatilidade, o merca- } \\
\text { do de etanol responde rapidamente } \\
\text { aos choques; ausência de assimetria } \\
\text { de choques }\end{array}$ \\
\hline $\begin{array}{l}\text { Castro Júnior } \\
\text { e Silva (2013) }\end{array}$ & $\begin{array}{l}\text { Analisar os retornos } \\
\text { do óleo de girassol, } \\
\text { enfatizando o risco } \\
\text { de mercado, medido } \\
\text { pelo comportamen- } \\
\text { to condicional da } \\
\text { variância }\end{array}$ & $\begin{array}{c}\text { Séries de preços mensais (1960 } \\
\text { - 2011) obtidas na base de } \\
\text { dados do IPEA; aplicação dos } \\
\text { modelos ARCH, GARCH e } \\
\text { TARCH }\end{array}$ & $\begin{array}{l}\text { Variabilidade dos retornos possui } \\
\text { dependência condicional, baixa } \\
\text { persistência na resposta aos choques } \\
\text { na variância, reduzindo riscos de } \\
\text { produção com relação aos preços dos } \\
\text { produtores }\end{array}$ \\
\hline $\begin{array}{l}\text { Ferreira, Da- } \\
\text { niel e Lima } \\
\quad(2016)\end{array}$ & $\begin{array}{l}\text { Verificar se os preços } \\
\text { da mamona na Bahia } \\
\text { estão sujeitos à } \\
\text { instabilidade e se a } \\
\text { implementação do } \\
\text { Programa Nacional } \\
\text { de Produção e Uso } \\
\text { do Biodiesel elevou } \\
\text { tal instabilidade }\end{array}$ & $\begin{array}{l}\text { Séries de preços semanais, } \\
\text { oriundos da Secretaria de } \\
\text { Agricultura da Bahia (2002 - } \\
\text { 2011); aplicação de modelos } \\
\text { TGARCH e EGARCH }\end{array}$ & $\begin{array}{l}\text { Preços da mamona na Bahia são ins- } \\
\text { táveis, aumentos nos preços elevam } \\
\text { a instabilidade e PNPB aumentou o } \\
\text { risco de preço no estado }\end{array}$ \\
\hline
\end{tabular}

Fonte: Elaboração própria com base nos autores mencionados.

O presente artigo recorre às mesmas técnicas de estatísticas dos trabalhos descritos, entendendo que a Econometria oferece instrumentos relevantes para caracterizar e examinar a volatilidade das séries de retornos dos produtos agropecuários. A originalidade deste artigo reside na opção pelo exame dos produtos da indústria canavieira (açúcar cristal, etanol anidro e etanol hidratado). Não obstante, a existência de estudos sobre a cana-de-açúcar (CAMPOS; PIACENTI, 2007) 
e o etanol (MARGARIDO; AZEVEDO; SHIKIDA, 2012) permite à literatura ressentir-se contemplada por uma análise dos produtos do setor sucroalcooleiro de modo abrangente. Entende-se que essa última opção, ora adotada, justifica-se pela importância desse setor na economia brasileira. Adicionalmente, o presente artigo abrange um período não analisado nos trabalhos citados - final de 2002 a meados de 2016 -, captando os impactos da recente crise mundial e da política energética, adotada no primeiro governo Dilma, sobre a indústria sucroenergética.

\section{Metodologia}

\subsection{Modelo econométrico}

Os modelos econométricos tradicionais supõem que a variância da estrutura de erros se mantém constante ao longo do tempo. No entanto, as séries econômicas podem apresentar períodos de pequena volatilidade seguidos de períodos de acentuada volatilidade. Nesses casos, a variância dos erros de previsão altera-se de um período para outro e a hipótese de homocedasticidade não mais se sustenta (MARGARIDO; AZEVEDO; SHIKIDA, 2012).

Campos (2007) aponta que séries econômicas, como preços de ativos, taxas de inflação, taxas de câmbio, dentre outras, apresentam valores que oscilam consideravelmente ao longo do tempo. Nos mercados financeiros e de commodities, por exemplo, tal variabilidade pode ser explicada pelas mudanças nas políticas econômicas domésticas e externas, bem como nas relações internacionais de comercialização de produtos. Em geral, observa-se que as séries relacionadas a esses mercados não possuem uma distribuição normal-padrão, dada a elevada probabilidade da ocorrência de choques externos.

Para capturar a autocorrelação na variância das perturbações, Engle (1982) desenvolveu o modelo autorregressivo de heterocedasticidade condicional (ARCH). Esse modelo foi posteriormente generalizado por Bollerslev (1986) com o GAR$\mathrm{CH}$, originando uma vasta literatura sobre o assunto. Uma das principais razões para o surgimento dessas modelagens econométricas foi a introdução de questões relacionadas ao risco e à incerteza na teoria econômica moderna.

Neste trabalho, são estimadas três extensões do modelo original desenvolvido por Engle (1982), a saber, os modelos GARCH, IGARCH e TARCH. A variância condicional fornecida por essas estimações é utilizada como proxy para a volatilidade das séries de retorno das commodities investigadas. 


\subsubsection{Modelo ARCH}

O modelo ARCH foi desenvolvido por Engle (1982) a fim de estimar a variância da inflação no Reino Unido. Sua premissa básica é a de que o retorno de um ativo qualquer não é correlacionado serialmente, mas a variância condicional (volatilidade) é a função quadrática dos retornos passados. Campos (2007) descreve que a ideia principal do modelo $\mathrm{ARCH}$ é o fato de que a variância do erro no período de tempo $t, \varepsilon_{t}$, depende do quadrado do termo de erro no período imediatamente anterior, $\varepsilon_{\mathrm{t}-1}^{2}$.

Considere o seguinte modelo autorregressivo:

$$
y_{t}=\alpha_{0}+\alpha_{1} y_{t-1}+\varepsilon_{t}
$$

Supondo que a variância da equação (1) não seja constante ao longo do tempo, é possível modelar essa variância por meio de um processo ARMA de ordem , utilizando o quadrado dos resíduos estimados:

$$
\hat{\varepsilon}_{\mathrm{t}}^{2}=\alpha_{0}+\alpha_{1} \hat{\varepsilon}_{\mathrm{t}-1}^{2}+\alpha_{2} \hat{\varepsilon}_{\mathrm{t}-2}^{2}+\ldots++\alpha_{\mathrm{p}} \hat{\varepsilon}_{\mathrm{t}-\mathrm{p}}^{2}+\mathrm{v}_{\mathrm{t}}
$$

considerando que $\mathrm{v}_{\mathrm{t}}$ constitui um ruído branco ${ }^{4}$.

Se os valores de $\alpha_{1}, \alpha_{2}, \ldots, \alpha_{p}$, forem iguais a zero, então a variância estimada resume-se à constante, significando que a hipótese de homocedasticidade é válida. Caso contrário, a variância condicional de $y_{t}$ é um processo do tipo autorregressivo e a equação (2) pode ser utilizada para se prever a variância condicional no período $\mathrm{t}+1$ :

$$
\mathrm{E}_{\mathrm{t}}\left[\hat{\varepsilon}_{\mathrm{t}+1}^{2}\right]=\alpha_{0}+\alpha_{1} \hat{\varepsilon}_{\mathrm{t}}^{2}+\alpha_{2} \hat{\varepsilon}_{\mathrm{t}-1}^{2}+\ldots+\alpha_{\mathrm{p}} \hat{\varepsilon}_{\mathrm{t}+1-\mathrm{p}}^{2}
$$

Conforme destacam Margarido, Azevedo e Shikida (2012), a especificação linear apresentada na equação (2) não é a mais conveniente, sendo mais tratável especificar o termo de erro $v$ na forma multiplicativa. Engle (1982) propôs o seguinte modelo multiplicativo condicional heterocedástico:

$$
\varepsilon_{\mathrm{t}}=\mathrm{v}_{\mathrm{t}} \sqrt{\alpha_{0}+\alpha_{1} \varepsilon_{\mathrm{t}-1}^{2}}
$$

${ }_{4}$ Um processo white noise ou ruído branco é identicamente e independentemente distribuído, com média zero. A sua função de autocorrelação (FAC) é igual a zero para todas as defasagens, exceto para a defasagem de ordem zero. Um ruído branco completamente aleatório implica na inpossibilidade de prever seu comportamento por meio de qualquer processo de estimação (MARGARIDO; AZEVEDO; SHIKIDA, 2012). 
em que é um processo ruído branco, tal que $\sigma_{\mathrm{v}}^{2}=1, \varepsilon_{\mathrm{t}}$ e $\mathrm{v}_{\mathrm{t}}$ são independentes um do outro. Ademais, para garantir que a variância condicional seja positiva, algumas restrições sobre os parâmetros são necessárias: $\alpha_{0}>0$ e $0<\alpha_{1}<1$.

A equação (4) representa um modelo autorregressivo de ordem 1 (somente choques no período $\mathrm{t}-1$ afetam o comportamento da sequência $\varepsilon$ no período $t$ ), podendo ser estendido para ordens mais elevadas. Nesse caso, o modelo é denominado $\mathrm{ARCH}(p)$ :

$$
\varepsilon_{\mathrm{t}}=\mathrm{v}_{1} \sqrt{\alpha_{0}+\sum_{\mathrm{i}=1}^{\mathrm{p}} \alpha_{\mathrm{i}} \varepsilon_{\mathrm{t}-1}^{2}}
$$

A equação (5) abrange os diversos choques localizados nos períodos de $\varepsilon_{\mathrm{t}-1}$ até $\varepsilon_{\mathrm{t}-\mathrm{p}}$ e que produzem diferentes impactos sobre o comportamento de $\varepsilon_{\mathrm{t}}$.

\subsubsection{Modelo GARCH}

Uma generalização do modelo ARCH foi sugerida por Bollerslev (1986), o chamado modelo GARCH (generalized ARCH). Bollerslev (1986) utilizou um modelo autorregressivo de médias móveis (ARMA) ao invés de um modelo autorregressivo conforme proposto anteriormente por Engle (1982). A opção por essa modelagem é explicada pelo fato de um modelo ARCH, de ordem mais elevada, possuir uma representação GARCH mais parcimoniosa, uma vez que há menos parâmetros a serem estimados (MARGARIDO; AZEVEDO; SHIKIDA, 2012).

Um modelo GARCH pode ser representado por:

$$
\begin{aligned}
& \varepsilon_{\mathrm{t}}=\mathrm{v}_{1} \sqrt{\mathrm{h}_{\mathrm{t}}} \\
& \text { na qual } \alpha_{\mathrm{v}}^{2}=1 \mathrm{e} \\
& \mathrm{h}_{\mathrm{t}}=\alpha_{0}+\sum_{\mathrm{i}=1}^{\mathrm{p}} \alpha_{\mathrm{i}} \varepsilon_{\mathrm{t}-1}^{2}+\sum_{\mathrm{j}=1}^{\mathrm{q}} \beta_{\mathrm{i}} \mathrm{h}_{\mathrm{t}-\mathrm{j}}
\end{aligned}
$$

As seguintes restrições são necessárias para garantir valores positivos para a variância condicional: $\mathrm{p} \geq 0, \alpha_{0}>0, \alpha_{i} \geq 0(i=1,2, \ldots, q)$ e $\beta_{i} \geq 0(j=1,2, \ldots, p)$. Ademais,

$$
\sum_{i, j=1}^{m}\left(\alpha_{i}+\beta_{j}\right)<1, m=\max (q, p)
$$


Dado que $v_{t}$ é um ruído branco, o qual é independente dos erros passados, então as médias condicional e incondicional de $\varepsilon_{t}$ são iguais a zero. Tomando-se a esperança de (6), tem-se:

$$
\mathrm{E}\left[\varepsilon_{\mathrm{t}}\right]=\mathrm{E}\left[\mathrm{v}_{\mathrm{t}} \sqrt{\mathrm{h}_{\mathrm{t}}}\right]=0
$$

A variância condicional de $\varepsilon_{\mathrm{t}}$ é igual a $\mathrm{E}_{\mathrm{t}-1}\left[\varepsilon_{\mathrm{t}}^{2}\right]=\mathrm{h}_{\mathrm{t}}$. Isso implica ao fato de que a variância condicional de $\varepsilon_{t}$ é dada por $h_{t}$ conforme apresentado na equação (7).

$\mathrm{O}$ modelo GARCH descreve a variância condicional de uma série de retornos como dependente de uma constante $\left(\alpha_{0}\right)$, com informações defasadas de volatilidade $\left(\right.$ os termos $\varepsilon_{t}$ ) e de variâncias previstas passadas (os termos $h_{t-j}$ ). A inclusão de variâncias condicionais defasadas objetiva capturar a aprendizagem adaptativa que pode caracterizar o processo (SILVA; SÁFADI; CASTRO JÚNIOR, 2005).

No modelo GARCH $(p, q)$, p representa a ordem do componente $\mathrm{ARCH}$ (componente autorregressivo) e q a ordem do componente GARCH (componente de médias móveis). Quando $p=1$ e $q=0$, tem-se um modelo ARCH de primeira ordem conforme representado pela equação (4), que é simplesmente um modelo GARCH $(1,0)$. Se todos os $\beta_{\mathrm{j}}$ são iguais a zero, o modelo GARCH $(p, q)$ é equivalente ao modelo ARCH (p).

As magnitudes dos coeficientes estimados para $\alpha_{\mathrm{i}}$ e $\beta_{\mathrm{j}}$ em conjunto determinam as dinâmicas de curto prazo da série de tempo em função de sua respectiva volatilidade. A persistência de choques na volatilidade da série de retornos é medida pela soma desses coeficientes. O somatório que apresenta um valor baixo, próximo de zero, indica que um choque inicial sobre a volatilidade provocará efeitos rápidos sob o comportamento da série e que, após um curto período de tempo, sua variância convergirá em sua média histórica. Quanto mais próximo da unidade for o valor desse somatório, mais vagarosamente o choque sobre a volatilidade se dissipará e maior será o tempo necessário para que a variância convirja em sua média (CAMPOS, 2007; MARGARIDO; AZEVEDO; SHIKIDA, 2012).

\subsubsection{Modelo IGARCH}

Nas aplicações do modelo GARCH $(1,1)$, observou-se que não raro a soma dos parâmetros $\alpha_{\mathrm{i}}$ e $\beta_{\mathrm{j}}$ é muito próxima à unidade. Tal fato levou Engle e Bollerslev (1986) a desenvolverem o modelo IGARH (integrated GARCH). Nesse modelo, um choque em um instante no tempo influencia ou permanece por um período longo de previsão. Os autores verificaram essa persistência na volatilidade dos retornos das bolsas (ENGLE; BOLLERSLEV, 1986).

A condição para que o modelo GARCH seja integrado é a de que: 


$$
\sum_{i=1}^{p} \alpha_{i}+\sum_{j=1}^{q} \beta_{i}=1
$$
modo:

A equação da variância no modelo IGARCH pode ser escrita do seguinte

$$
h_{t}=\alpha_{0}+\sum_{i=1}^{p} \alpha_{1} \varepsilon_{t-1}^{2}+\sum_{j=1}^{q}\left(1-\alpha_{i}\right) h_{t-j}
$$

\subsubsection{Modelo TARCH}

Os modelos ARCH/GARCH tratam da variância dos retornos de maneira simétrica, já que ambos modelam a volatilidade utilizando uma função quadrática dos retornos. Entretanto, as evidências empíricas revelam que as variações negativas dos retornos dos ativos apresentam um peso maior do que as variações positivas, ao passo que a volatilidade associada a um choque negativo é maior do que a volatilidade associada a um choque positivo. Disso apreende-se o caráter assimétrico da volatilidade.

Existem diversas variações dos modelos ARCH/GARCH que tratam a variância de maneira assimétrica. Zakoian (1994), por exemplo, propôs o modelo autorregressivo de heterocedasticidade condicional truncado (TARCH), o qual pode ser expresso da seguinte forma:

$$
h_{t}=\alpha_{0}+\sum_{i=1}^{p} \alpha_{1} \varepsilon_{t-1}^{2}+\sum_{j=1}^{q} \beta_{j} h_{t-j}+\sum_{k=1}^{r} \gamma_{k} d_{t-k} \varepsilon_{t-k}^{2}
$$

em que é uma variável binária, assume os seguintes valores:

$$
d_{t-k}=\left\{\begin{array}{l}
1, \text { se } \varepsilon_{t-k}<0 \\
0, \text { caso contrário. }
\end{array}\right.
$$

Portanto, o efeito de choques positivos, $\varepsilon_{\mathrm{t}-\mathrm{k}}>0$, sobre a variância condicional é dado por $\alpha$ i, enquanto que o efeito de choques negativos, $\varepsilon_{t-k}<0$, é dado por $a_{i}+y_{k}$. Se o coeficiente for significativamente diferente de zero, diz-se que a variância condicional é assimétrica. Caso contrário, se $\gamma_{\mathrm{k}}=0$, não há assimetria. 


\subsection{Descrição e fonte dos dados}

Utilizaram-se dados secundários correspondentes às séries de preços médios semanais, recebidos pelos produtores de açúcar cristal ( $\mathrm{R} \$ / \mathrm{saca}$ de $50 \mathrm{~kg}$ ), etanol anidro e etanol hidratado (R \$/litro), de São Paulo. Os valores referem-se, portanto, aos negócios efetivados entre as usinas sucroalcooleiras, localizadas no estado de São Paulo, e os compradores/distribuidoras. Os dados foram obtidos do Centro de Estudos Avançados em Economia Aplicada da Escola Superior de Agricultura "Luiz de Queiroz" (CEPEA/ESALQ). Para o açúcar cristal, tais dados abrangem o período compreendido entre 20 de maio de 2003 e 10 de maio de 2016, totalizando 675 observações. Os dados referentes ao etanol anidro e etanol hidratado abrangem o período entre 29 de novembro de 2002 e 06 de maio de 2016, totalizando 702 observações para cada um desses produtos.

Para modelar a volatilidade dos retornos gerados pelas commodities, calcularam-se os retornos compostos continuamente ou log-retornos. O retorno semanal do preço à vista das séries foi obtido aplicando-se a equação (11):

$$
\mathrm{R}_{\mathrm{t}}=\operatorname{In}\left(\mathrm{P}_{\mathrm{t}}\right)-\operatorname{In}\left(\mathrm{P}_{\mathrm{t}-1}\right)
$$

em que é o retorno semanal do preço à vista da commodity examinada, $\operatorname{In}\left(\mathrm{P}_{\mathrm{t}}\right)$ é o logaritmo natural do preço no período $t$ e In $\left(\mathrm{P}_{\mathrm{t}-1}\right)$ é o logaritmo natural do preço no período imediatamente anterior.

Com os retornos semanais de todas as séries obtidos, pôde-se, então, estimar os modelos e realizar inferências estatísticas. O software utilizado para esse exercício foi o EVieres 7, da IHS Inc.

\section{Resultados e discussão}

O Gráfico 1 ilustra o comportamento das séries de preços e retornos do açúcar cristal, etanol anidro e etanol hidratado no período de análise.

Gráfico 1 - Séries de preços e de retornos semanais recebidos por produtores de São Paulo: açúcar cristal (20/05/2003 a 10/05/2016), etanol anidro e hidratado $(29 / 11 / 2002$ a $06 / 05 / 2016)$
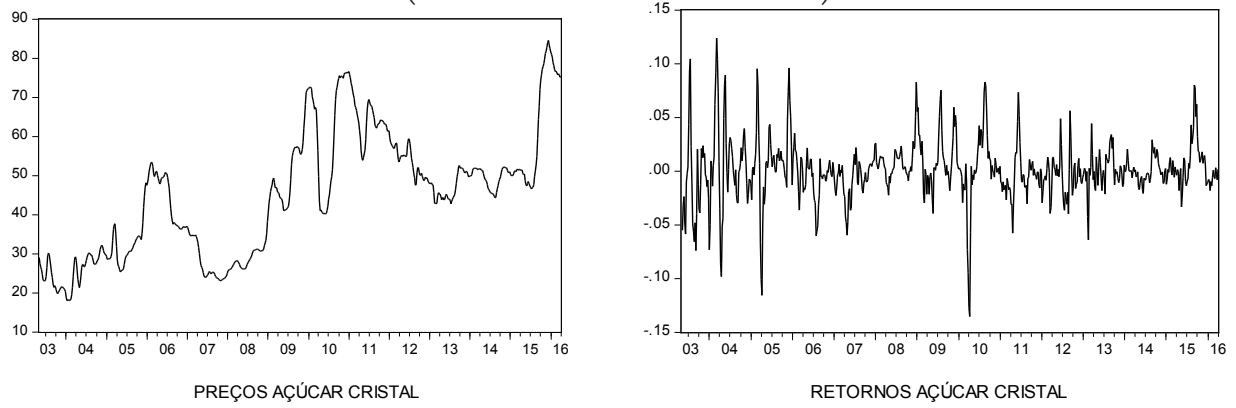

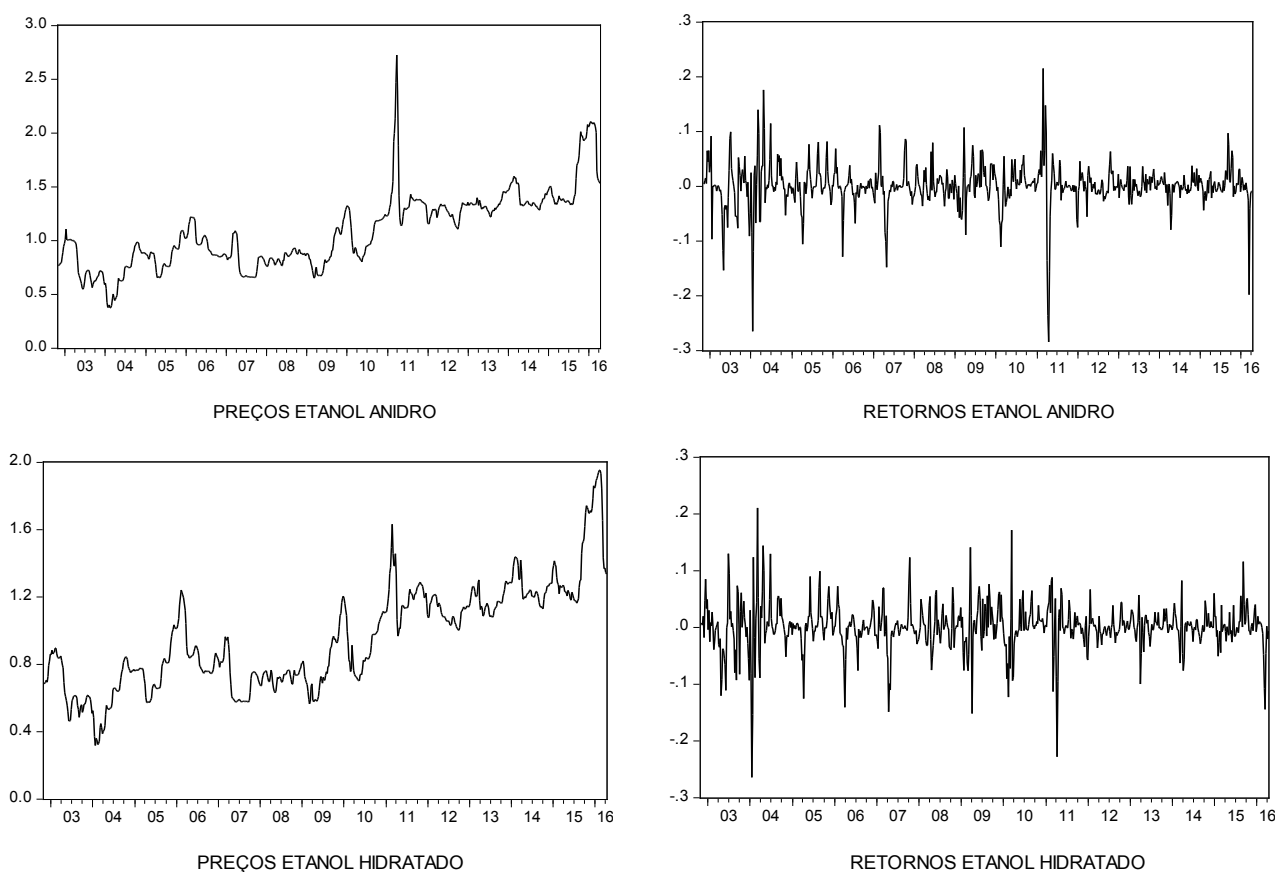

Fonte: Resultados da pesquisa.

As estatísticas descritivas para as séries de retornos dos produtos examinados são reportadas na Tabela 2.

Tabela 2 - Estatísticas descritivas - Séries de retornos semanais recebidos por produtores de São Paulo: açúcar cristal (20/05/2003 a 10/05/2016), etanol anidro e hidratado $(29 / 11 / 2002$ a 06/05/2016)

\begin{tabular}{cccc}
\hline Estatísticas & Açúcar Cristal & Etanol Anidro & Etanol Hidratado \\
\hline Média & 0,001415 & 0,000985 & 0,000956 \\
Mediana & 0,000631 & 0,000759 & 0,000781 \\
Desvio-Padrão & 0,027997 & 0,040134 & 0,040983 \\
Assimetria & 0,089062 & $-1,201329$ & $-0,628989$ \\
Curtose & 7,239153 & 14,38831 & 9,688141 \\
Teste Jarque-Bera & 505,5604 & 3956,745 & 1352,747 \\
Probabilidade $(J B)$ & 0,00000 & 0,000000 & 0,000000 \\
Observações & 674 & 701 & 701 \\
\hline
\end{tabular}

Fonte: Resultados da pesquisa.

A assimetria retrata o grau de afastamento de uma distribuição em relação ao 
eixo de referência traçado sobre o valor de sua média. No caso da série de retornos do açúcar cristal, dado que a média é maior que a mediana, tem-se uma assimetria à direita equivalente a 0,08. A curtose de 7,23 indica que a série de retornos apresenta uma distribuição leptocúrtica. Juntamente com a representação gráfica do comportamento dos preços e dos retornos ao longo do período de análise, essas medidas descritivas sugerem que a série do açúcar cristal exibe sinais de heterocedasticidade e de agrupamento de volatilidade. Adicionalmente, o teste de normalidade de Jarque-Bera permite concluir que os dados não possuem distribuição normal.

Por meio da análise das estatísticas descritivas referentes ao etanol anidro e ao etanol hidratado, verificou-se que as séries de retornos desses dois produtos também apresentam indícios de heterocedasticidade e de agrupamento de volatilidade: o teste Jarque-Bera rejeita a hipótese nula de que as amostras foram extraídas de uma distribuição normal; o coeficiente de assimetria é diferente de zero, com a presença de assimetria negativa; a análise de curtose indica que ambas as séries de retornos possuem distribuição leptocúrtica em relação à normal.

O primeiro procedimento foi ajustar um modelo de médias para cada uma das séries de retornos, regredindo-se a variável dependente contra um termo constante. A fim de confirmar a evidência de que a volatilidade das séries possui um padrão ARCH, efetuou-se o teste do tipo multiplicador de Lagrange, proposto por Engle (1982), nos resíduos dos modelos ajustados. Os $p$-valores do teste, reportados na Tabela 3, fornecem fortes indícios contra a hipótese nula de não haver heterocedasticidade condicional nas séries de retornos dos produtos investigados.

Tabela 3 - Teste ARCH, de Engle, das séries de retornos semanais recebidos por produtores de São Paulo: açúcar cristal (20/05/2003 a 10/05/2016), etanol anidro e hidratado $(29 / 11 / 2002$ a 06/05/2016)

\begin{tabular}{cc|cc|cc}
\hline \multicolumn{2}{c|}{ Resíduos / Açúcar Cristal } & \multicolumn{2}{|c|}{ Resíduos / Etanol Anidro } & \multicolumn{2}{c}{ Resíduos / Etanol Hidratado } \\
\hline Defasagens & Prob. & Defasagens & Prob. & Defasagens & Prob. \\
1 & 0,0000 & 1 & 0,0000 & 1 & 0,0000 \\
5 & 0,0000 & 5 & 0,0000 & 5 & 0,0000 \\
10 & 0,0000 & 10 & 0,0000 & 10 & 0,0000 \\
20 & 0,0000 & 20 & 0,0000 & 20 & 0,0000 \\
\hline
\end{tabular}

Fonte: Resultados da pesquisa.

A Tabela 4 contém as estimativas dos coeficientes das funções de autocorrelação (FAC) e de autocorrelação parcial (FACP) para os retornos e retornos ao quadrado do açúcar cristal, do etanol anidro e hidratado. As respectivas estatísticas Q (teste Ljung-Box) possuem probabilidades próximas a zero, levando à rejeição das respectivas hipóteses nulas de que os resíduos não estão autocorrelacionados. Isso significa que observações adjacentes são correlacionadas, em conformidade com a presença do efeito ARCH nas séries: quando os mercados dos produtos examinados sofrem oscilações significativas, a variância das séries se amplia por um período determinado, criando agrupamentos temporários de observações autocorrelacionadas. 
Tabela 4 - Estimativas dos coeficientes das funções FAC e FACP para as séries de retornos semanais recebidos por produtores de São Paulo: açúcar cristal (20/05/2003 a 10/05/2016), etanol anidro e hidratado (29/11/2002 a 06/05/2016)

\begin{tabular}{|c|c|c|c|c|c|c|c|c|c|}
\hline \multicolumn{5}{|c|}{ Retornos - açúcar cristal } & \multicolumn{5}{|c|}{ Retornos quadráticos - açúcar cristal } \\
\hline $\mathrm{k}$ & FAC & FACP & Q-Stat & Prob & $\mathrm{k}$ & FAC & FACP & Q-Stat & Prob \\
\hline 1 & 0,790 & 0,790 & 422,01 & 0,000 & 1 & 0,688 & 0,688 & 320,75 & 0,000 \\
\hline 2 & 0,502 & $-0,322$ & 592,85 & 0,000 & 2 & 0,316 & $-0,301$ & 388,26 & 0,000 \\
\hline 3 & 0,262 & $-0,021$ & 639,63 & 0,000 & 3 & 0,130 & 0,115 & 399,81 & 0,000 \\
\hline 4 & 0,074 & $-0,091$ & 643,38 & 0,000 & 4 & 0,123 & 0,105 & 410,03 & 0,000 \\
\hline 5 & $-0,040$ & 0,014 & 644,44 & 0,000 & 5 & 0,175 & 0,069 & 430,94 & 0,000 \\
\hline 6 & $-0,079$ & 0,023 & 648,71 & 0,000 & 6 & 0,148 & $-0,071$ & 445,93 & 0,000 \\
\hline 7 & $-0,085$ & $-0,026$ & 653,60 & 0,000 & 7 & 0,072 & $-0,003$ & 449,48 & 0,000 \\
\hline 8 & $-0,078$ & $-0,016$ & 657,71 & 0,000 & 8 & 0,042 & 0,055 & 450,67 & 0,000 \\
\hline 9 & $-0,062$ & 0,000 & 660,32 & 0,000 & 9 & 0,055 & 0,007 & 452,73 & 0,000 \\
\hline 10 & $-0,070$ & $-0,079$ & 663,68 & 0,000 & 10 & 0,050 & $-0,044$ & 454,46 & 0,000 \\
\hline \multicolumn{5}{|c|}{ Retornos - etanol anidro } & \multicolumn{5}{|c|}{ Retornos quadráticos - etanol anidro } \\
\hline $\mathrm{k}$ & FAC & FACP & Q-Stat & Prob & $\mathrm{k}$ & FAC & FACP & Q-Stat & Prob \\
\hline 1 & 0,569 & 0,569 & 228,09 & 0,000 & 1 & 0,451 & 0,451 & 142,93 & 0,000 \\
\hline 2 & 0,225 & $-0,147$ & 263,75 & 0,000 & 2 & 0,167 & $-0,046$ & 162,48 & 0,000 \\
\hline 3 & 0,091 & 0,042 & 269,65 & 0,000 & 3 & 0,138 & 0,101 & 175,96 & 0,000 \\
\hline 4 & 0,024 & $-0,33$ & 270,04 & 0,000 & 4 & 0,121 & 0,032 & 186,27 & 0,000 \\
\hline 5 & $-0,66$ & $-0,093$ & 273,17 & 0,000 & 5 & 0,068 & $-0,006$ & 189,58 & 0,000 \\
\hline 6 & $-0,152$ & $-0,095$ & 289,51 & 0,000 & 6 & 0,132 & 0,122 & 201,90 & 0,000 \\
\hline 7 & $-0,182$ & $-0,057$ & 313,11 & 0,000 & 7 & 0,226 & 0,143 & 238,29 & 0,000 \\
\hline 8 & $-0,140$ & 0,005 & 327,05 & 0,000 & 8 & 0,099 & $-0,091$ & 245,21 & 0,000 \\
\hline 9 & $-0,082$ & 0,004 & 331,83 & 0,000 & 9 & 0,046 & 0,021 & 246,69 & 0,000 \\
\hline 10 & $-0,044$ & $-0,004$ & 333,22 & 0,000 & 10 & 0,013 & $-0,054$ & 246,81 & 0,000 \\
\hline \multicolumn{5}{|c|}{ Retornos - etanol hidratado } & \multicolumn{5}{|c|}{ Retornos quadrát. - etanol hidratado } \\
\hline $\mathrm{k}$ & FAC & FACP & Q-Stat & Prob & $\mathrm{k}$ & FAC & FACP & Q-Stat & Prob \\
\hline 1 & 0,448 & 0,448 & 141,05 & 0,000 & 1 & 0,286 & 0,286 & 57,751 & 0,000 \\
\hline 2 & 0,060 & $-0,176$ & 143,58 & 0,000 & 2 & 0,146 & 0,069 & 72,679 & 0,000 \\
\hline 3 & 0,039 & 0,111 & 144,66 & 0,000 & 3 & 0,066 & 0,009 & 75,796 & 0,000 \\
\hline 4 & 0,081 & 0,032 & 149,33 & 0,000 & 4 & 0,071 & 0,045 & 79,389 & 0,000 \\
\hline 5 & 0,021 & $-0,045$ & 149,63 & 0,000 & 5 & 0,088 & 0,058 & 84,888 & 0,000 \\
\hline 6 & $-0,096$ & $-0,100$ & 156,20 & 0,000 & 6 & 0,105 & 0,063 & 92,715 & 0,000 \\
\hline 7 & $-0,121$ & $-0,039$ & 166,60 & 0,000 & 7 & 0,220 & 0,179 & 127,10 & 0,000 \\
\hline 8 & $-0,079$ & $-0,024$ & 171,07 & 0,000 & 8 & 0,056 & $-0,070$ & 129,33 & 0,000 \\
\hline 9 & $-0,054$ & $-0,019$ & 173,17 & 0,000 & 9 & 0,046 & 0,006 & 130,85 & 0,000 \\
\hline 10 & $-0,49$ & $-0,007$ & 174,87 & 0,000 & 10 & 0,057 & 0,038 & 133,20 & 0,000 \\
\hline
\end{tabular}


A partir das evidências/estatísticas de que os modelos mais adequados para as séries de retornos da indústria canavieira são modelos heterocedásticos, o próximo passo consistiu no ajuste de um conjunto de regressões das respectivas variâncias condicionais. É importante lembrar que a presença do efeito ARCH implica no fato de que a variância das séries não é constante e, por conseguinte, os resultados de eventuais testes aplicados sobre tais séries, a fim de avaliar a hipótese de existência de raiz unitária, são viesados. Dada a impossibilidade de se testar a estacionariedade das séries, as defasagens das respectivas regressões não puderam ser identificadas com base na análise dos correlogramas. Sendo assim, recorreu-se aos critérios de informação de Akaike, Schwarz e Hannan-Quinn para a seleção das defasagens. A Tabela 5 apresenta os critérios de informação associados aos diferentes modelos estimados.

Tabela 5 - Critérios de Informação de modelos estimados para as séries de retornos semanais recebidos por produtores de São Paulo: açúcar cristal (20/05/2003 a

10/05/2016), etanol anidro e hidratado (29/11/2002 a 06/05/2016)

\begin{tabular}{|c|c|c|c|}
\hline \multicolumn{4}{|c|}{ SÉRIE RETORNOS AÇÚCAR CRISTAL } \\
\hline $\begin{array}{c}\text { Critério Informa- } \\
\text { ção }\end{array}$ & $\begin{array}{c}\mathrm{AR}(1) / \\
\operatorname{GARCH}(1,1)\end{array}$ & $\begin{array}{c}\operatorname{AR}(1) \operatorname{AR}(2) / \\
\operatorname{GARCH}(1,1)\end{array}$ & $\begin{array}{r}\operatorname{AR}(1) \operatorname{AR}(2) / \\
\operatorname{GARCH}(1,2)\end{array}$ \\
\hline AKAIKE & $-5,604939$ & $-5,639340$ & $-5,637424$ \\
\hline SCHWARZ & $-5,578124$ & $-5,605782$ & $-5,597154$ \\
\hline $\begin{array}{l}\text { HANNAN- } \\
\text {-QUINN }\end{array}$ & $-5,594555$ & $-5,626344$ & $-5,621828$ \\
\hline \multicolumn{4}{|c|}{ SÉRIE RETORNOS ETANOL ANIDRO } \\
\hline $\begin{array}{c}\text { Critério Informa- } \\
\text { ção }\end{array}$ & $\begin{array}{c}\operatorname{AR}(1) / \\
\operatorname{IGARCH}(1,1)\end{array}$ & $\begin{array}{l}\operatorname{AR}(1) \operatorname{AR}(2) / \\
\operatorname{IGARCH}(1,1)\end{array}$ & $\begin{array}{l}\operatorname{AR}(1) \operatorname{AR}(6) / \\
\operatorname{IGARCH}(1,1)\end{array}$ \\
\hline AKAIKE & $-4,056168$ & $-4,077679$ & $-4,080724$ \\
\hline SCHWARZ & $-4,043165$ & $-4,058153$ & $-4,061110$ \\
\hline $\begin{array}{l}\text { HANNAN- } \\
\text {-QUINN }\end{array}$ & $-4,051141$ & $-4,070131$ & $-4,073140$ \\
\hline \multicolumn{4}{|c|}{ SÉRIE RETORNOS ETANOL HIDRATADO } \\
\hline $\begin{array}{l}\text { Critério Informa- } \\
\text { ção } \\
\end{array}$ & $\begin{array}{c}\operatorname{AR}(1) / \\
\operatorname{IGARCH}(1,1)\end{array}$ & $\begin{array}{l}\operatorname{AR}(1) \operatorname{AR}(2) / \\
\operatorname{IGARCH}(1,1) \\
\end{array}$ & $\begin{array}{l}\operatorname{AR}(1) \operatorname{AR}(2) / \\
\operatorname{IGARCH}(1,2)\end{array}$ \\
\hline AKAIKE & $-3,933105$ & $-3,954724$ & $-3,853201$ \\
\hline SCHWARZ & $-3,920102$ & $-3,935197$ & $-3,827166$ \\
\hline $\begin{array}{l}\text { HANNAN- } \\
\text {-QUINN }\end{array}$ & $-3,928078$ & $-3,947175$ & $-3,843136$ \\
\hline
\end{tabular}

Fonte: Resultados da pesquisa. 
Com base na condição de minimização dos critérios de informação e nas vantagens de modelos parcimoniosos, identificou-se que o melhor modelo para o açúcar cristal foi um $\mathrm{AR}(1)$ e $\mathrm{AR}(2)$ para a classe $\mathrm{GARCH}(1,1)$, com os parâmetros estatisticamente relevantes ao nível de significância de $1 \%$. Para os demais produtos, constatou-se um AR(1) e AR(6) para o etanol anidro, e um $\operatorname{AR}(1)$ e $\operatorname{AR}(2)$ para o etanol hidratado, dados os modelos da classe $\operatorname{IGARCH}(1,1) .{ }^{5}$ Nestes últimos casos, os parâmetros também mostraram-se estatisticamente significativos a 1\%. Em seguida, analisou-se os correlogramas dos resíduos padronizados e dos quadrados dos resíduos padronizados para cada modelo ajustado, e verificou-se uma ausência de heterocedasticidade condicional nos resíduos desses modelos.

A estimação do GARCH/IGARCH permitiu captar a dinâmica da volatilidade das séries de retornos. As condições observadas para que a variância do processo seja positiva e fracamente estacionária são as de que os parâmetros de regressão sejam positivos e maiores do que zero. $\mathrm{Na}$ equação de variância, o parâmetro representado por "RESID $(-1)^{\wedge} 2^{2}$ " constitui o coeficiente de reação da volatilidade, enquanto que o parâmetro "GARCH(-1)", o coeficiente de persistência da volatilidade ou o risco na série de retorno.

Os resultados das estimativas (Tabela 6) mostram que o valor do coeficiente de reação associado ao açúcar cristal é igual a 0,36, ao mesmo tempo que o valor do coeficiente de persistência é 0,54 , ambos significativos a $1 \%$. Isso revela uma persistência de choques moderada sobre a volatilidade dos retornos desse produto. Para o etanol anidro, obteve-se um coeficiente de reação equivalente a 0,05 , a passo que para o etanol hidratado esse mesmo coeficiente é 0,10 . Os coeficientes de persistência estimados, 0,94 para o etanol anidro e 0,89 para o etanol hidratado, revelam que os choques na variância levam muito tempo para se dissiparem, isto é, possuem elevada persistência temporal. Todos esses coeficientes são estatisticamente relevantes ao nível de significância de $1 \%$.

\footnotetext{
Após a estimação dos modelos GARCH para as séries de retornos semanais do etanol anidro e hidratado, verificou-se que a soma dos coeficientes das respectivas equações de variância excedia a unidade. Sendo assim, foi utilizado como base o modelo IGARCH, respeitando-se, portanto, a restrição de que a soma dos parâmetros estimados seja igual à unidade.
} 
Tabela 6 - Estimação do Modelo GARCH/IGARCH para as séries de retornos semanais recebidos por produtores de São Paulo: açúcar cristal (20/05/2003 a 10/05/2016), etanol anidro e hidratado (29/11/2002 a 06/05/2016)

\begin{tabular}{|c|c|c|c|c|}
\hline \multicolumn{5}{|c|}{ SÉRIE RETORNOS AÇÚCAR CRISTAL - GARCH $(1,1)$} \\
\hline & Coeficiente & Erro-Padrão & Estatística z & Probabilidade \\
\hline $\operatorname{AR}(1)$ & 0,928560 & 0,041192 & 22,54281 & 0,0000 \\
\hline $\operatorname{AR}(2)$ & $-0,211022$ & 0,043222 & $-4,882324$ & 0,0000 \\
\hline \multicolumn{5}{|c|}{ Equação de Variância } \\
\hline $\mathrm{C}$ & $3,31 \mathrm{E}-05$ & $4,08 \mathrm{E}-06$ & 8,121358 & 0,0000 \\
\hline $\begin{array}{c}\text { RE- } \\
\operatorname{SID}(-1)^{\wedge} 2\end{array}$ & 0,366361 & 0,054277 & 6,749797 & 0,0000 \\
\hline GARCH(-1) & 0,549993 & 0,041116 & 13,37652 & 0,0000 \\
\hline \multicolumn{5}{|c|}{ SÉRIE RETORNOS ETANOL ANIDRO - IGARCH $(1,1)$} \\
\hline & Coeficiente & Erro-Padrão & Estatística z & Probabilidade \\
\hline $\operatorname{AR}(1)$ & 0,601069 & 0,021835 & 27,52811 & 0,0000 \\
\hline $\operatorname{AR}(6)$ & $-0,114446$ & 0,030557 & $-3,745304$ & 0,0002 \\
\hline
\end{tabular}

Equação de Variância

\begin{tabular}{|c|c|c|c|c|}
\hline $\begin{array}{c}\text { RE- } \\
\operatorname{SID}(-1)^{\wedge} 2\end{array}$ & 0,052749 & 0,0003326 & 15,85833 & 0,0000 \\
\hline GARCH $(-1)$ & 0,947251 & 0,0003326 & 284,7787 & 0,0000 \\
\hline
\end{tabular}

SÉRIE RETORNOS ETANOL HIDRATADO - IGARCH $(1,1)$

\begin{tabular}{ccccc}
\hline & Coeficiente & Erro-Padrão & Estatística $\mathbf{z}$ & Probabilidade \\
\hline $\operatorname{AR}(1)$ & 0,612745 & 0,027128 & 22,58745 & 0,0000 \\
$\operatorname{AR}(2)$ & $-0,181845$ & 0,027576 & $-6,594247$ & 0,0000 \\
\hline
\end{tabular}

Equação de Variância

$\begin{array}{ccccc}\text { RE- } & 0,102654 & 0,004351 & 23,59394 & 0,0000 \\ \operatorname{SID}(-1)^{\wedge} 2 & & 0,004351 & 206,2461 & 0,0000 \\ \text { GARCH(-1) } & 0,897346 & 0\end{array}$

Fonte: Resultados da pesquisa.

Tais resultados não corroboram o trabalho de Margarido, Azevedo e Shikida (2012). Esses autores concluíram que, apesar da alta volatilidade, o mercado de etanol é capaz de responder rapidamente aos choques. De acordo com eles, a explicação desse processo encontra-se intimamente relacionada às características de oferta e demanda por etanol. Do lado da oferta, visto que na maior parte das usinas há alguma flexibilidade de alocação da cana para a produção de açúcar ou etanol, os usineiros podem arbitrar entre as duas commodities, conforme sua rentabilidade. 
Essa arbitragem constitui uma importante fonte de dissipação do choque. Do lado da demanda, inovações tecnológicas, concernentes ao desenvolvimento dos motores de combustão flexfuel, permitem aos proprietários de automóveis alterarem a composição da relação gasolina/etanol consumidos. Sendo assim, choques de preço sobre o etanol podem ser atenuados por alterações no consumo de gasolina (MARGARIDO; AZEVEDO; SHIKIDA, 2012).

Cabe aventar algumas possíveis razões para essa divergência de resultados. Enquanto o trabalho de Margarido, Azevedo e Shikida (2012) compreendeu os anos de 2002 a 2010, o presente artigo estendeu o período analisado até meados de 2016, abrangendo os impactos mais duradouros da recente crise econômica e financeira mundial sobre o setor sucroalcooleiro no Brasil, bem como os efeitos das políticas energéticas adotadas no primeiro governo Dilma, particularmente o controle de preços da gasolina. É razoável supor que a falência de inúmeras usinas no contexto de crise internacional e de perda de competitividade do etanol - devida ao controle de preços da gasolina - influenciou o modo como os preços se ajustam. De um lado, o processo de concentração no setor sucroenergético decorrente das falências impactou na oferta, antes pulverizada entre um número maior de usinas. De outro, os patamares de preço em que a gasolina foi mantida contribuiu para agravar a situação adversa do setor, marcada pela perda de competitividade do etanol combustível, que só seria viável aos consumidores com preços impraticáveis pelos produtores já impactados pela crise internacional. Nesse cenário, embora os usineiros continuassem arbitrando entre a produção de açúcar e de álcool, a eficiência dessa arbitragem na dissipação de choques se reduziu.

Do lado da demanda, sabe-se que, devido a questões relacionadas à eficiência dos motores, entre outras, o preço do etanol combustível deve estar significativamente abaixo do preço da gasolina, seu substituto direto no caso dos automóveis flexfuel, para conquistar a preferência dos consumidores. Dessa forma, choques de preço podem ter significativa persistência. Outro fator que concorre para esse resultado é o fato de que a demanda por etanol anidro mantém uma relação direta com a demanda por gasolina: considerando que a gasolina deve conter um percentual de etanol anidro definido pelo Ministério de Minas e Energia, é possível tomá-los como bens complementares. Logo, a demanda por etanol anidro é, de certa maneira, "garantida", o que contribui para que o mecanismo de mitigação dos choques de preço não atue tão efetivamente nesse produto, já que a legislação nacional garante que ele será o aditivo usado na gasolina, em detrimento de outros, o que implica que ele não está exposto à concorrência de produtos alternativos.

Em suma, é provável que fatores tanto do lado da demanda quanto do lado da oferta influenciaram, nos últimos anos, a persistência de choques sobre o preço dos produtos da indústria canavieira. Disso apreende-se a maior temporalidade relativa exigida para que a variância condicional do etanol anidro e hidratado convirja à sua média histórica.

Com base nos resultados obtidos por meio da estimação do modelo GAR$\mathrm{CH} / \mathrm{IGARCH}$, o Gráfico 2 ilustra o comportamento do desvio-padrão condicional para cada uma das séries de retornos dos produtos no período examinado. A análise gráfica revela que níveis mais elevados de volatilidade são encontrados na série do 
açúcar cristal. A maior persistência temporal dos choques, por sua vez, ocorre nas séries do etanol anidro e hidratado.

Gráfico 2 - Desvio-Padrão Condicional obtido da modelagem GARCH/IGAR$\mathrm{CH}$ para as séries de retornos semanais recebidos por produtores de São Paulo: açúcar cristal (20/05/2003 a 10/05/2016), etanol anidro e hidratado (29/11/2002 a 06/05/2016)
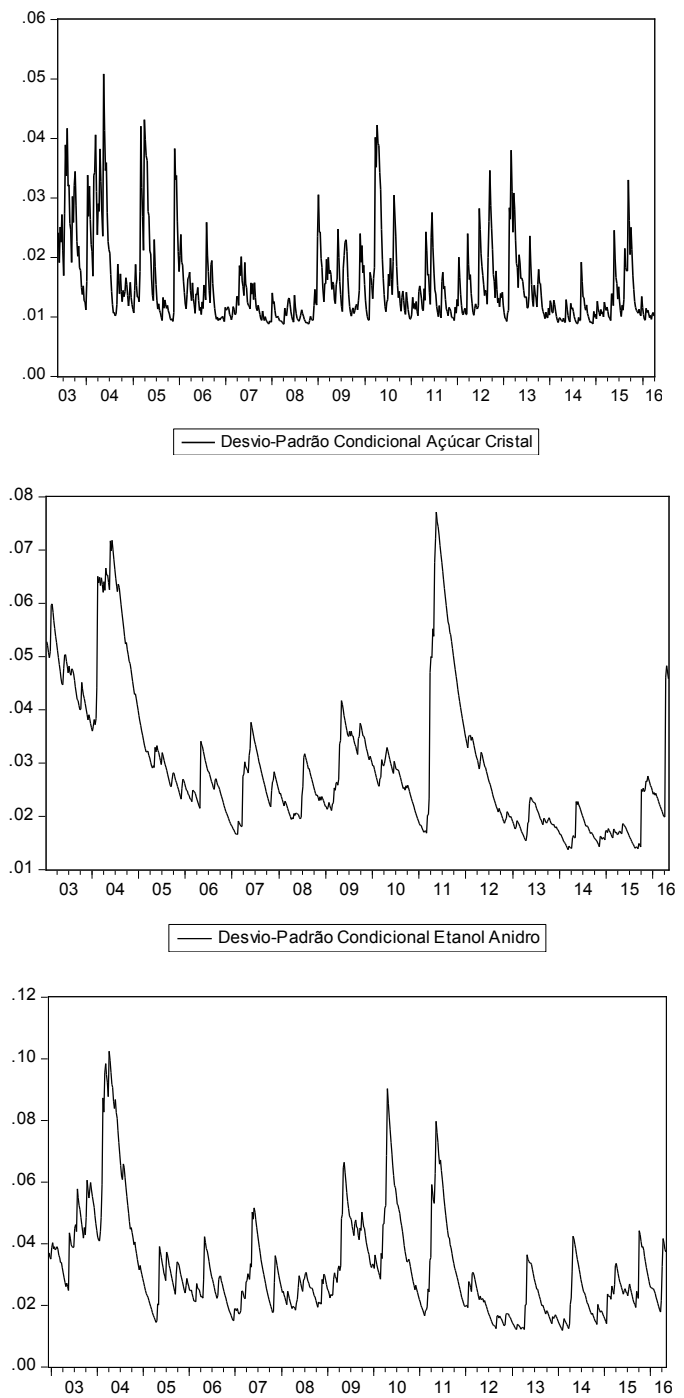

Fonte: Resultados da pesquisa. 
Por fim, visando testar a presença de assimetria proporcionada por choques, foi estimado o modelo TARCH $(1,1)$ para as séries de retornos. Seus resultados são reportados na Tabela 7. Considerando os critérios de informação e as vantagens de modelos parcimoniosos, a estimação das regressões para as séries de retornos do açúcar cristal e do etanol hidratado mantiveram as defasagens utilizadas no ajuste dos modelos GARCH/IGARCH. No caso do etanol anidro, foi necessária uma reformulação das defasagens para garantir as hipóteses do modelo TARCH: substituição do termo $\mathrm{AR}(6)$ por $\mathrm{AR}(5)$ (os novos critérios de informação de Akaike, Schwarz e Hannan-Quinn são, respectivamente, -4,3822; -4,343; e -4,3671).

Tabela 7 - Estimação do Modelo TARCH para as séries de retornos semanais recebidos por produtores de São Paulo: açúcar cristal (20/05/2003 a 10/05/2016), etanol anidro e hidratado (29/11/2002 a 06/05/2016) [1]

\begin{tabular}{|c|c|c|c|c|}
\hline \multicolumn{5}{|c|}{ SÉRIE RETORNOS AÇÚCAR CRISTAL - TARCH $(1,1)$} \\
\hline & Coeficiente & Erro-Padrão & Estatística z & Probabilidade \\
\hline $\operatorname{AR}(1)$ & 0,930458 & 0,042867 & 21,70557 & 0,0000 \\
\hline $\operatorname{AR}(2)$ & $-0,211207$ & 0,042248 & $-4,999248$ & 0,0000 \\
\hline \multicolumn{5}{|c|}{ Equação de Variância } \\
\hline $\mathrm{C}$ & $3,12 \mathrm{E}-05$ & $4,21 \mathrm{E}-06$ & 7,427393 & 0,0000 \\
\hline $\operatorname{RESID}(-1) \wedge 2$ & 0,308074 & 0,052113 & 5,911700 & 0,0000 \\
\hline $\operatorname{RESID}(-1) \wedge 2 *(\operatorname{RESID}(-1)<0)$ & 0,132737 & 0,078058 & 1,700490 & 0,0890 \\
\hline GARCH(-1) & 0,558150 & 0,039255 & 14,21873 & 0,0000 \\
\hline
\end{tabular}

SÉRIE RETORNOS ETANOL ANIDRO - TARCH $(1,1)$

\begin{tabular}{ccccc}
\hline & Coeficiente & Erro-Padrão & Estatística z & Probabilidade \\
\hline $\operatorname{AR}(1)$ & 0,435329 & 0,029534 & 14,73992 & 0,0000 \\
$\operatorname{AR}(5)$ & $-0,079169$ & 0,014136 & $-5,600365$ & 0,0000 \\
\hline \multicolumn{5}{c}{ Equação de Variância } \\
\hline C & 0,000277 & $2,12 \mathrm{E}-05$ & 13,07847 & 0,0000 \\
RESID(-1)^2 & 1,086889 & 0,121136 & 8,972493 & 0,0000 \\
GARCHD(-1)^2*(-1) & 0,025325 & 0,138032 & 0,183473 & 0,8544 \\
& 0,079916 & 0,032387 & 2,467543 & 0,0136
\end{tabular}

SÉRIE RETORNOS ETANOL HIDRATADO - TARCH(1,1)

\begin{tabular}{ccccc}
\hline & Coeficiente & Erro-Padrão & Estatística z & Probabilidade \\
\hline $\mathrm{AR}(1)$ & 0,545609 & 0,042013 & 12,98669 & 0,0000 \\
$\mathrm{AR}(2)$ & $-0,019289$ & 0,036237 & $-0,532296$ & 0,5945 \\
\hline \multicolumn{5}{c}{ Equação de Variância } \\
\hline $\mathrm{C}$ & 0,000198 & $2,12 \mathrm{E}-05$ & 9,353581 & 0,0000 \\
$\mathrm{RESID}(-1)^{\wedge} 2$ & 0,648832 & 0,097414 & 6,660543 & 0,0000 \\
$\mathrm{RESID}(-1)^{\wedge} 2^{*}(\operatorname{RESID}(-1)<0)$ & 0,079650 & 0,125337 & 0,635491 & 0,5251 \\
$\operatorname{GARCH}(-1)$ & 0,327861 & 0,044131 & 7,429340 & 0,0000 \\
\hline
\end{tabular}

Fonte: Resultados da pesquisa. 
O modelo TARCH fornece evidências de que não há assimetria na volatilidade dos retornos dos preços desses produtos, uma vez que o coeficiente da equação $(10)$ - na Tabela 6, representado por “RESID $(-1) \wedge 2 *(\operatorname{RESID}(-1)<0)$ ”, não se mostrou significativamente diferente de zero ao nível de $5 \%$ para cada um deles. Sendo assim, choques positivos e negativos não produzem impactos distintos sobre a volatilidade, confirmando a não presença de assimetria. A investigação realizada por Margarido, Azevedo e Shikida (2012) também encontrou fortes evidências contra a hipótese de choques assimétricos sobre o preço do etanol anidro.

\section{Considerações finais}

Tentativas de fornecer subsídios para o delineamento de estratégias adequadas para o gerenciamento do risco de variações nos preços de commodities agrícolas, com base em métodos econométricos, são apresentadas em diversos trabalhos. Nessa mesma direção, o presente artigo procurou caracterizar a volatilidade das séries de retornos semanais dos produtos da indústria canavieira, dada a importância desse segmento no agronegócio brasileiro e sua participação na pauta exportadora. Para tanto, foram utilizadas extensões dos modelos ARCH.

A realização do teste ARCH, proposto por Engle (1982), apresentou fortes evidências de que as séries de retornos dos produtos investigados apresentam heterocedasticidade condicional, implicando nos distúrbios irregulares em seus preços, estes podem provocar períodos de instabilidade no setor sucroalcooleiro. A estimação do modelo GARCH/IGARCH corroborou tais evidências. A análise dos coeficientes de reação e de persistência obtidos permitiu concluir que níveis mais elevados de volatilidade são encontrados na série do açúcar cristal. A maior persistência temporal dos choques, por sua vez, ocorre nas séries do etanol anidro e hidratado. O modelo TARCH forneceu fortes indícios de que não há assimetria na volatilidade dos retornos dos preços das três commodities. Isso implica que choques positivos e negativos não produzem impactos distintos sobre esses mercados.

Considerando o contexto da crise econômica mundial, a reorientação da política energética brasileira e o controle de preços da gasolina no primeiro governo Dilma, o setor sucroenergético foi fortemente impactado. Em primeiro lugar, como destacado por Wilkinson (2015), a situação financeira das usinas canavieiras tornou-se crítica no pós-crise, com dificuldades de custeio e uma onda de falências, que levou a uma maior concentração no setor. Em segundo lugar, as mudanças do papel desempenhado pelo álcool na matriz energética - passando por um momento favorável na década de 1980 e um declínio nos anos 1990, seu auge no início do milênio e a perda de fôlego no período recente, com a crise financeira mundial, a descoberta do pré-sal e a política de preços da gasolina - revelam a instabilidade presente nesse setor ao longo de sua história. Em decorrência dessas condições, com diversos choques afetando a trajetória da produção sucroenergética, seus preços apresentam alta 
volatilidade e elevada persistência temporal.

Algumas questões são levantadas a partir da análise desenvolvida, podendo ser tratadas em trabalhos futuros. Entre elas, pode-se destacar a relação entre as volatilidades dos preços internacionais do petróleo e dos produtos aqui investigados. Nesse sentido, o GARCH Multivariado pode ser empregado para avaliar o comportamento das variâncias das séries, ensejando um maior entendimento sobre os efeitos da orientação da matriz energética para materiais fósseis ou biocombustíveis.

\section{Referências}

BBC BRASIL. Quatro fatores para entender a crise do etanol. BBC Brasil, 2013. Disponível em: <http://www.bbc.com/portuguese/noticias/2013/05/130424_etanol_ mdb >. Acesso em: jun. 2016.

BOLLERSLEV, T. Generalized Autoregressive Conditional Heteroscedasticity. Journal of Econometrics, v. 31, n. 3, p. 307-327, 1986. crossrefhttps://doi. org/10.1016/0304-4076(86)90063-1

CAMPOS, K. C. Análise da volatilidade de preços de produtos agropecuários no Brasil. Revista de Economia e Agronegócio, v. 5, n. 3, p. 303-327, 2007.

CAMPOS, K. C.; PIACENTI, C. A. Agroenergia: a questão da volatilidade de preços e o efeito alavancagem dos produtos agrícolas. In: Congresso Brasileiro de Economia e Sociologia Rural, 45, Londrina, 2007. Anais... Londrina: SOBER, 2007.

CASTRO, L. S.; SILVA JÚNIOR, A. G. Análise da volatilidade de preços do óleo de girassol no Brasil de 1960 a 2011. Revista de Política Agrícola, v. 22, n. 2, p. 76-84, 2013.

CONAB (Companhia Nacional de Abastecimento). Séries históricas. CONAB, 2016. Disponível em: $<$ http://www.conab.gov.br/conteudos.php? $=1252 \& t=2>$. Acesso em: jun. 2016.

ENGLE, R. F. Autoregressive Conditional Heteroskedasticity with Estimates of the Variance of United Kingdom Inflation. Econometrica, v. 50, n. 4, p. 987-1007, jul. 1982. crossref https://doi.org/10.2307/1912773

ENGLE, R. F.; BOLLERSLEV, T. Modeling the Persistence of Conditional Variances. Econometric Reviews, v. 5, n. 1, p. 1-50, 1986. crossref https://doi. org/10.1080/07474938608800095 
FERREIRA, M. D. P.; DANIEL, L. P.; LIMA, J. P. E. O programa brasileiro de biodiesel e o risco associado ao preço da mamona em Irecê, Bahia. Revista de Economia e Sociologia Rural, Piracicaba, v. 53, n. 4, p. 667-682, 2016. crossref https://doi. org/10.1590/1234-56781806-9479005304006

FURTADO, A. T.; CORTEZ, L. A. B.; SCANDIFFIO, M. I. G. O sistema de inovação da agroindústria canavieira brasileira. In: Congresso Brasileiro de Planejamento Energético, 6, Salvador, 2008. Anais... Salvador, 2008, p. 887-905.

JOÃO, I. S.; PORTO, G. S.; GALINA, S. V. R. A posição do Brasil na corrida pelo etanol celulósico: mensuração por indicadores C\&T e programas de P\&D. Revista Brasileira de Inovação, Campinas, v. 11, n. 1, p. 105-136, jan./jun. 2012. crossref https://doi.org/10.20396/rbi.v11i1.8649028

LEITE, R. C. C.; LEAL, M. R. L. V. O biocombustível no Brasil. Novos Estudos CEBRAP, v. 78, p. 15-21, jul. 2007. crossref https://doi.org/10.1590/S010133002007000200003

MARGARIDO, M. A.; AZEVEDO, P. F.; SHIKIDA, P. F. A. Eficiência e coordenação oligopolista no mercado de etanol anidro no Estado de São Paulo: uma aplicação dos modelos ARCH/GARCH. In: KON, A.; BORELLI, E. (Org.). Indústria, Tecnologia e Trabalho: desafios da economia brasileira. São Paulo: EITT/PUC, v.1, 2012, p. 293-317.

MATTOS, L. B.; CASSUCE, F. C. C.; MÜLLER, C. A. S. Análise da volatilidade do retorno mensal de boi gordo: 1967-2005. Unimontes Científica, Montes Claros, v. 8 , n. 1, p. 99-106, jan./jun. 2006.

SAITH, W.; KAMITANI, E. L. T. Volatilidade e assimetria de choques no mercado agropecuário brasileiro: um uso dos modelos da família GARCH. Tecnologia e Ciência Agropecuária, João Pessoa, v. 6, n. 1, p. 1-7, mar. 2012.

SILVA, W. S.; SÁFADI, T.; CASTRO JÚNIOR, L. G. Uma análise empírica da volatilidade do retorno de commodities agrícolas utilizando modelos ARCH: os casos do café e da soja. Revista de Economia e Sociologia Rural, v. 43, n. 1, p. 119-134, jan./ mar. 2005. crossref https://doi.org/10.1590/S0103-20032005000100007

UNICA (União da Indústria de Cana-de-Açúcar). Fotografia do setor sucroenergético no Brasil. UNICA, 2015. Disponível em: < http://www.unica.com.br/documentos/documentos >. Acesso em: jun. 2016. 
WILKINSON, J. O setor sucroalcooleiro brasileiro na atual conjuntura nacional $e$ internacional. Rio de Janeiro: Recife: Action Aid Brasil, 2015. Disponível em: $<$ http://www.actionaid.org.br/sites/files/actionaid/setor_sucroalcooleiro_port_ rev.pdf $>$. Acesso em: jun. 2016.

ZAKOIAN, J. M. Threshold Heteroskedasticity Models. Journal of Economic Dynamic and Control, v. 18, n. 5, p. 931-955, 1994. crossref https://doi. org/10.1016/0165-1889(94)90039-6

Recebido em 06.12.16

Aprovado em 04.07.17 
